Max-Planck-Institut für demografische Forschung

Max Planck Institute for Demographic Research

Konrad-Zuse-Strasse 1 - D-18057 Rostock · GERMANY

Tel +49 (0) 3812081 - 0; Fax +49 (0) 3812081 - 202;

http://www.demogr.mpg.de

MPIDR TECHNICAL REPORT 2012-004

AUGUST 2012

\title{
Episode Data \\ from the Russian Education and Employment Survey
}

Michaela Kreyenfeld (kreyenfeld@demogr.mpg.de)

Dirk Konietzka

For additional material see www.demogr.mpg.de/tr/

(C) Copyright is held by the authors.

Technical reports of the Max Planck Institute for Demographic Research receive only limited review. Views or opinions expressed in technical reports are attributable to the authors and do not necessarily reflect those of the Institute. 


\title{
Episode Data from the Russian Education and Employment Survey
}

\author{
Michaela Kreyenfeld und Dirk Konietzka
}

\begin{abstract}
This paper documents how to generate consistent education, employment, fertility and residential careers from the Russian Employment and Education Survey (EES). We describe how we imputed missing or inaccurate data. Furthermore, we estimate a first birth model to demonstrate how this data could be used for event history modelling. A sensitivity analysis shows that the results are very stable in respect to the imputation of missing dates. Data is organized in spell or episode format. For manipulating the data, we used the software STATA 10.0.
\end{abstract}

Keywords: Life course data, education, employment, fertility 


\section{Introduction}

This paper is a documentation of how we generated employment, education and residential careers from the Russian Education and Employment Survey (EES). The EES is a subsample of the Russian Generations and Gender Survey (GGS). ${ }^{1}$ It provides longitudinal information on respondents' employment, education, fertility and residential histories. It is a retrospective survey and it includes biographical information since January of the year the respondents turned age 17 (for details, see Independent Institute for Social Policy 2005). The virtue of the data set is the accuracy with which it surveys employment and educational careers. For example, it allows for multiple activities, such as second jobs.

In this paper, we provide an overview of how the raw EES-data can be transferred into episode format so that they can be used for event history modelling. The paper is organized as follows. In the following section (part 2), we show how we generated the careers and how we imputed missing or implausible data. Part 3 describes how we joined the various careers into a single data set. Part 4 provides an example of how to use this data for event history modelling. In that part, we also conduct a sensitivity analysis. The data is assembled in spell or episode format. For data manipulation, we used STATA 10.0. The command syntax is available with the Technical Report. The code may be used by other users by citing this document. However, we hold no responsibility for errors that may have arisen during the coding procedures.

\section{Generating Educational, Employment and Fertility Careers}

In this section, we explain the principle of how we manipulated the raw data. We draw on the educational career to explain the data set-up. For generating the other careers, we proceeded in a similar fashion. We generated each career separately and finally integrated them in a single data set. We opted for this step-by-step procedure,

The data may be merged by a personal identifier with the GGS-data. Due to data protection reasons, the personal identifier is not available in the scientific use file of the EES data. However, a data file that contains EES and GGS data is available upon request. 
because it makes it easier to detect errors and miscoding in the data. Altogether, we generated the following seven careers (or biographies) from the raw data:

(1) The educational biography

(2) The main job biography

(3) The second job biography

(4) The other activity biography

(5) The unemployment benefit biography

(6) The residential biography

(7) The fertility biography

\subsection{The main data set-up}

Table 1 provides a data extract from the EES data. It shows the main educational career of the first respondent in the data set (with the personal identification number bid 101009). On the basis of this respondent, we show how we manipulated the raw data. Here, we selected only the variables related to the respondent's education to simplify matters. As the table depicts, the respondent started his or her first education in January 1971. This first activity ends in June 1972. There is one more educational episode (from September 1972 until June 1976). The remaining rows in this data extract provide only missing information since they refer to other activities, such as employment. 
Table 1: Educational career in the raw data

\begin{tabular}{|ccccccc|}
\hline bid & o9s_m & 09s_y & o9k_m & 09k_y & o11 & bh4y \\
\hline 101009 & january & 1971 & & & secondary & 1954 \\
101009 & & & & & & 1954 \\
101009 & & & june & 1972 & & 1954 \\
101009 & & & & & & 1954 \\
101009 & september & 1972 & & & Higher & 1954 \\
101009 & & & june & \multirow{2}{*}{1976} & & 1954 \\
101009 & & & & & & 1954 \\
101009 & & & & & & 1954 \\
101009 & & & & & & 1954 \\
101009 & & & & & & 1954 \\
101009 & & & & & & 1954 \\
101009 & & & & & 1954 \\
101009 & & & & & 1954 \\
101009 & & & & & & 1954 \\
\hline
\end{tabular}

Notes: bid: Personal identification number; o9s_m: Month start of education; o9s_y: Year start of education; o9k_m: Month end of education; 09s_y: Year end of education; o11: Type of education; bh4y: Year of birth

In a first step, we selected all rows which contain information on the start and ending of an education spell. Furthermore, we joined the beginning and the end of an educational episode into one row.

Table 2: Educational career after joining beginning and end of episode

\begin{tabular}{|ccccccc|}
\hline bid & 09s_m & 09s_y & o9k_m & o9k_y & o11 & bh4y \\
\hline 101009 & January & 1971 & June & 1972 & Secondary & 1954 \\
101009 & September & 1972 & June & 1976 & Higher & 1954 \\
\hline
\end{tabular}

Notes: bid: Personal identification number; o9s_m: Month start of education; o9s_y: Year start of education; o9k_m: Month end of education; 09s_y: Year end of education; o11: Type of education; bh4y: Year of birth

In the next step, we generated two new variables. BEGIN denotes the beginning of an episode, measured in months since January of the year the respondent turned age 17. END denotes the end of an episode, also measured in months since January of the year the respondent turned age 17 (see Table 3). 
Table 3: Educational career after using respondent's age as process time

\begin{tabular}{|cccc|}
\hline bid & BEGIN & END & 011 \\
\hline 101009 & 1 & 18 & Secondary \\
101009 & 21 & 66 & Higher \\
\hline
\end{tabular}

Notes: bid: Personal identification number; BEGIN: Start of the episode in person months since January of the year the respondent turned age 17; END: End of the episode in person months since January of the year the respondent turned age 17; o11: Type of education

In the next step, we subtracted one month from BEGIN (see Table 4). This procedure is consistent with the idea that respondents mean the period January $1^{\text {st }}$ until June $30^{\text {th }}$ when they report that they were employed from January until June. It also fits the notion that a new job or a new education is usually started at the beginning of a month. However, for some cases ending month and starting date of the subsequent episode were the same. For such cases, we assumed that a change of activity occurred in the middle of the month.

Table 4: Educational career after subtracting one month from beginning of episode

\begin{tabular}{|cccc|}
\hline Bid & BEGIN & END & 011 \\
\hline 101009 & 0 & 18 & Secondary \\
101009 & 20 & 66 & Higher \\
\hline
\end{tabular}

Notes: bid: Personal identification number; BEGIN: Start of the episode in person months since January of the year the respondent turned age 17; END: End of the episode in person months since January of the year the respondent turned age 17; o11: Type of education

In a final step, we filled the gaps within the educational career (see Table 5). For filling the gaps, we used the Stata-Ado-File "Spellsort” (Walke and Kreyenfeld 2006).

Table 5: Educational career after filling the gaps

\begin{tabular}{|cccc|}
\hline Bid & BEGIN & END & 011 \\
\hline 101009 & 0 & 18 & Secondary \\
101009 & 18 & 20 & -1 \\
101009 & 20 & 66 & higher: \\
\hline
\end{tabular}

Notes: bid: Personal identification number; BEGIN: Start of the episode in person months since January of the year the respondent turned age 17; END: End of the episode in person months since January of the year the respondent turned age 17; o11: Type of education

There are some respondents who did not report any educational episode. All educational variables were set to missing (-1) for these respondents. Unfortunately, it is not possible to distinguish between different types of missing information. We are 
therefore not able to differentiate respondents who never received any education from respondents who failed to report their educational career (non-response). This applies to all other careers as well.

For some episodes, only starting and ending times, but no further information was given. In order to identify episodes from the educational career in the final data set, we generated a variable called EDU which is equal to 1 for all educational episodes (and -1 otherwise). For the other careers, we generated similar variables. An exception is the fertility career. Only the dates of childbirth, but no further information on children is provided. For respondents who did not report a date of childbirth, we had to assume that these respondents are childless. As mentioned before, more accurate fertility histories may be derived from the Generations and Gender Survey which may be linked to the EES data.

\subsection{How cases with missing or inaccurate information on month of occurrence of event were treated}

There are some cases, where respondents did not report the exact date of occurrence of an event, but only the quarter or the half of the year. This issue is exemplified in Table 6 which displays the frequency count of the month of the beginning of the educational episode. We recoded the inaccurate monthly information based on a random procedure. For example, respondents who report that they started a new educational spell in the first quarter of the year were assigned a random month variable that has the values one, two or three. Respondents who report that they started a new educational spell in the second quarter of the year were assigned a random variable that has the values four, five or six.

This procedure can produce overlaps when ending times are larger than subsequent starting times. We adjusted the ending times in all cases where starting and ending times did not join. Episodes in the educational career which have been recoded have been flagged out by a variable called IMP_EDU. IMP_EDU equals 1 for “beginning recoded”, 2 for “end recoded”, 3 for "beginning and end recoded” and 4 for “end adjusted”. 
Table 6: Distribution of the month of beginning of educational episode

\begin{tabular}{|lrr|}
\hline Month & Frequency & \multicolumn{2}{c|}{ Percent } \\
\hline january & 5,953 & 50.56 \\
february & 124 & 1.05 \\
march & 108 & 0.92 \\
april & 77 & 0.65 \\
may & 102 & 0.87 \\
june & 284 & 2.41 \\
july & 231 & 1.96 \\
august & 512 & 4.35 \\
september & 3,837 & 32.59 \\
october & 261 & 2.22 \\
november & 130 & 1.1 \\
december & 120 & 1.02 \\
1st quarter & 6 & 0.05 \\
2nd quarter & 5 & 0.04 \\
3rd quarter & 19 & 0.16 \\
4th quarter & 6 & 0.05 \\
& & \\
Total & 11,775 & 100 \\
\hline
\end{tabular}

\subsection{Miscellaneous}

\subsubsection{Unclear starting or ending dates}

The data structure of the EES is designed in a way that the starting date is given in the first row, the ending date in the subsequent row (see Table 1). There are some cases that violate this order. This is exemplified for a respondent in Table 7. This person entered his/her second educational period in his/her life in September 1999. Before the end of this episode is reported, a new educational episode is given. There is also a case where the first row is an ending date. Furthermore, there are cases where the last entry is a starting date. We recoded the data and flagged out cases by a variable called ODD_EDU. 
Table 7: Case with “odd” educational career

\begin{tabular}{|ccccccc|}
\hline bid & SPELL & o9s_m & 09s_y & o9k_m & 09k_y & o11 \\
\hline 925155 & 1 & January & 1999 & & & Secondary \\
925155 & 2 & & & June & 1999 & \\
925155 & 3 & September & 1999 & & & Higher \\
925155 & 4 & September & 2001 & & & Higher \\
925155 & 5 & & & 3rd quarter & 2001 & \\
925155 & 6 & & & December & 2003 & \\
\hline
\end{tabular}

Notes: bid: Personal identification number; SPELL: Row number; o9s_m: Month start of education; o9s_y: Year start of education; o9k_m: Month end of education; o9s_y: Year end of education; bh4y: Year of birth; o11: Type of education

\subsubsection{Peculiarities in the educational career}

There are 10 such cases (as described in Section 2.3.1) in the education career (out of 6.455 cases in the whole data set). Apart from this, we did not notice any peculiarities in the educational career.

\subsubsection{Peculiarities in the main employment career}

There were 60 such odd cases in the main employment career. Apart from cases as described in section 2.3.1, we did not notice any peculiarities in the main employment career.

\subsubsection{Peculiarities in the second job career}

There were 7 such odd cases in the second job career. Apart from cases as described in section 2.3.1, we did not notice any peculiarities in the second job career.

\subsubsection{Peculiarities in the other activity career}

In the other activity career, there are 64 cases as described in Section 2.3.1. There was one more case where the starting time was larger than the ending time (see Table 8). We deleted the erroneous episode and flagged out the case by the variable ODD_OTH. 
In general, we transferred all variables that were available into episode format. There is/was only one exception: we omitted the (string) variable "r32s" which refers to the other activity career from the data set.

Table 8: Case with peculiar other activity career

\begin{tabular}{|ccccc|}
\hline bid & r31s_m & r31s_y & r31k_m & r31k_y \\
\hline 4507010 & November & 1983 & & \\
4507010 & & & May & 1985 \\
4507010 & July & 2005 & & \\
4507010 & & & April & 2005 \\
\hline
\end{tabular}

Notes: bid: personal identification number; z31s_m: month start of other activity; z31s_y: year start of other activity; z31k_m: month end of other activity; z31k_y: year end of other activity

\subsubsection{Peculiarities in the unemployment benefit career}

Periods in which respondents received unemployment benefits have been organized in a slightly different way than the other careers. These periods were surveyed within the “other activity career”. For unemployment periods, the starting and ending dates are stored in the same row (see Table 9). We did not observe any peculiar cases in the unemployment career.

Table 9: Selected cases in the unemployment career

\begin{tabular}{|cccccc|}
\hline bid & r31sp_m & r31sp_y & r31kp_m & r31kp_y & r32s_c \\
\hline 102002 & november & 2004 & february & 2005 & br (unem \\
102008 & 2nd quar & 2003 & april & 2004 & br (unem \\
\hline
\end{tabular}

Notes: bid: personal identification number; z31sp_m: month start of unemployment; z31sp_y: year start of unemployment; z31kp_m: month end of unemployment; z31kp_y: year end of unemployment; r32s_c: type of occupation

\subsubsection{Peculiarities in the residential career}

In the residential careers, only starting dates were reported. We assumed that a respondent resided in a certain district until he/she reports the next starting date for another district. Similar to the other careers, we assumed that the change occurred at the beginning of the month. Since only starting dates were reported, the last episode was open. For this reason, we generated a censoring date. As the date of censoring, we used the last reported year and month that was given as an ending time in the employment, education or "other activity" career. There were 14 cases, where the last 
reported date was in the residential career. We censored the case at this date. For three cases, there were two similar dates of one move. We flagged out these cases by the variable ODD_MIG.

Table 10 shows a data extract from the residential career. Table 11 displays the career after manipulating the data.

Table 10: Data extract from the residential career

\begin{tabular}{|ccccccc|}
\hline bid & m4_y & m4_m & m5 & bh4y & CENSORY & CENSORM \\
\hline 111109 & 1966 & january & ukraina & 1949 & 2005 & 4 \\
111109 & 1976 & july & primorsk & 1949 & 2005 & 4 \\
111109 & 1983 & december & leningra & 1949 & 2005 & 4 \\
111109 & 1993 & october & ta zhe, & 1949 & 2005 & 4 \\
\hline
\end{tabular}

Notes: bid: Personal identification number; $\mathrm{m} 4 \_\mathrm{y}$ : Year start of residing in a new area; $\mathrm{m} 4 \mathrm{~m}$ : Month start of residing in a new area; m5: Region code; bh4y: Year of birth; CENSORY: Year of censoring; CENSORM: Month of censoring

Table 11: Data extract from the residential career after manipulating the data

\begin{tabular}{|cccc|}
\hline bid & BEGIN & END & m5 \\
\hline 111109 & 0 & 126 & ukraina \\
111109 & 126 & 215 & primorsk \\
111109 & 215 & 333 & leningra \\
111109 & 333 & 472 & ta zhe, \\
\hline
\end{tabular}

Notes: bid: Personal identification number; BEGIN: Start of the episode in person months since January of the year the respondent turned age 17; END: End of the episode in person months since January of the year the respondent turned age 17; m5: Region code

In a final step, we generated a cleaned variable that denotes the place of residence (m5new). We created it in a way that all labels of this variable provide the English name of the region. Furthermore, if a person reported "the same" (ta zhe), we use information on region that was provided in the previous spell of the respondent.

\subsubsection{Peculiarities in the fertility career}

In the EES, there is one variable for the year a child was born and another one for the month of childbirth. The data set-up is exemplified in Table 12. Based on the year and month of childbirth, we generated the fertility career, as shown in Table 12 and 13. We generated a new variable called PARITY which denotes the parity of he 
respondent. We also generated a censoring date similar to the censoring date we have used in the residential career (see section 2.3.7).

In the EES, only the date of birth is recorded. No further information on children is given; neither if the birth is a twin or triplet birth. This means that for higher order births, one is not able to determine the number of children of a respondent. Also births that occur before age 17 are not recorded in the data set. (Merging the EES-data to the GGS would provide more accurate fertility histories).

Table 12: Data extract from the fertility career

\begin{tabular}{|cccccc|}
\hline bid & y1 & Y3 & bh4y & CENSORY & CENSORM \\
\hline 111109 & 1969 & March & 1949 & 2005 & 4 \\
111109 & 1974 & July & 1949 & 2005 & 4 \\
111109 & 1977 & May & 1949 & 2005 & 4 \\
\hline
\end{tabular}

Notes: bid: Personal identification number; y1: year; y3: month of childbirth; bh4y: Year of birth of respondent; CENSORY: Year of censoring; CENSORM: Month of censoring

Table 13: Data extract from the fertility career after manipulating the data

\begin{tabular}{|cccc|}
\hline bid & BEGIN & END & PARITY \\
\hline 111109 & 0 & 39 & 0 \\
111109 & 39 & 103 & 1 \\
111109 & 103 & 137 & 2 \\
111109 & 137 & 473 & 3 \\
\hline
\end{tabular}

Notes: bid: Personal identification number; BEGIN: Start of the episode in person months since January of the year the respondent had turned age 17; END: End of the episode in person months since January of the year the respondent had turned age 17; PARITY: Number of births

\subsection{Merging the careers into a single episode data set}

In a final step, we merged the seven careers into a single episode data set. For joining the data, we used the Stata-Ado-file „Spelljoin” (Walke und Kreyenfeld 2006). Table 14 and 15 exemplify how we proceeded based on the first respondent in the data set (with the bid 101009). Tables 14a to 14d show the separate biographies. For improved readability, we only selected four files and only one control variable from each file. Table 15 finally shows the complete history. The final data set is saved as EES01_clean.dta. Before saving, we also "cleaned" the labels of the variables. The final data set includes 6,455 respondents (just like the original EES file). 
Table 14a: Data extract from the educational career

\begin{tabular}{|cccc|}
\hline bid & BEGIN & END & 011 \\
\hline 101009 & 0 & 18 & secondar \\
101009 & 18 & 20 & -1 \\
101009 & 20 & 66 & higher: \\
\hline
\end{tabular}

Table 14b: Data extract from the main employment career

\begin{tabular}{|cccc|}
\hline bid & BEGIN & END & z15 \\
\hline 101009 & 0 & 67 & -1 \\
101009 & 67 & 155 & professi \\
101009 & 155 & 236 & workers \\
101009 & 236 & 412 & professi \\
\hline
\end{tabular}

Table 14c: Data extract from the residential career

\begin{tabular}{|cccc|}
\hline bid & BEGIN & END & m5ew \\
\hline 101009 & 0 & 20 & Leningrad Oblast \\
101009 & 20 & 67 & Saint Petersburg \\
101009 & 67 & 412 & Leningrad Oblast \\
\hline
\end{tabular}

Table 14d: Data extract from the fertility career

\begin{tabular}{|cccc|}
\hline bid & BEGIN & END & PARITY \\
\hline 101009 & 0 & 171 & 0 \\
101009 & 171 & 412 & 1 \\
\hline
\end{tabular}

Table 15: Data extract from the final data set

\begin{tabular}{|ccccccc|}
\hline bid & BEGIN & END & 011 & z15 & m5new & PARITY \\
\hline 101009 & 0 & 18 & secondar & -1 & Leningrad Oblast & 0 \\
101009 & 18 & 20 & -1 & -1 & Leningrad Oblast & 0 \\
101009 & 20 & 66 & higher: & -1 & Saint Petersburg & 0 \\
101009 & 66 & 67 & -1 & -1 & Saint Petersburg & 0 \\
101009 & 67 & 155 & -1 & professi & Leningrad Oblast & 0 \\
101009 & 155 & 171 & -1 & workers & Leningrad Oblast & 0 \\
101009 & 171 & 236 & -1 & workers & Leningrad Oblast & 1 \\
101009 & 236 & 412 & -1 & professi & Leningrad Oblast & 1 \\
\hline
\end{tabular}




\section{An Application: Employment and Transition to First Birth}

\subsection{Descriptive statistics of employment pattern}

In this part, we demonstrate how to use the EES data to estimate a first birth model. To simplify matters, we only use two covariates: cohort and activity status. Table 16 provides the distribution of the cohort variable which we used for the analysis. Since this variable is a time-constant variable, we show the distribution by respondents (instead of person-months).

Table 16: Descriptive statistics of time-constant covariates

\begin{tabular}{|lll|}
\hline \multicolumn{2}{|c|}{ Males } & Females \\
\hline Cohort & & \\
$1948-1954$ & $13.7 \%$ & $17.9 \%$ \\
$1955-1959$ & $14.3 \%$ & $16.6 \%$ \\
$1960-1964$ & $14.5 \%$ & $16.3 \%$ \\
$1965-1969$ & $13.9 \%$ & $12.0 \%$ \\
$1970-1974$ & $13.3 \%$ & $12.9 \%$ \\
$1975-1979$ & $12.6 \%$ & $11.5 \%$ \\
$1980-1988$ & $17.6 \%$ & $12.8 \%$ \\
Total & $100 \%$ & $100 \%$ \\
Number of cases & 2,460 & 3,995 \\
\hline
\end{tabular}

In a next step, we generated a new variable which unifies the different activities into one variable. This new variable distinguishes between (1) periods of full-time education or periods of military service (2) periods of employment (3) periods of unemployment (4) periods of other activities and (5) periods of missing information. If there is an overlap of activities, we assigned a hierarchy (employment over education, education over unemployment and unemployment over other activity). Table 17 displays the distribution of the person months for this variable. The cases have not been censored at first birth. Therefore, the distribution gives the distribution of the activity status until time of interview. 
Table 17: Descriptive statistics of time constant covariates, person-months

\begin{tabular}{|lrrr|}
\hline & Males & Females & Total \\
\hline In Education & 103760 & 122959 & 226719 \\
Employment & 458786 & 799112 & 1257897 \\
Unemployment & 18919 & 16410 & 35329 \\
Other activity & 25845 & 85890 & 111734 \\
Missing & 11019 & 65055 & 76074 \\
& & & \\
Total person months & 618328 & 1089424 & 1707752 \\
\hline
\end{tabular}

\subsection{Descriptive statistics of first birth pattern ${ }^{2}$}

In this section, we describe the first birth pattern with the EES data. Altogether, we observe 5,063 first births. Figure 2a and Figure 2b displays Kaplan-Meier-survival curves by sex and cohort. Against the background of the societal transformation in Russia, one would expect a strong postponement of childbirth among younger cohorts. Particularly the cohorts who entered their reproductive period in the 1990s should show a pronounced differing childbearing pattern. However, the survival curves do not fully support this hypothesis.

Males of the cohorts 1948-1974 show a rather homogeneous pattern of an early first birth. The median age at first birth for males of these cohorts is age 25 . Only the cohorts born 1975 or later have their first child much later. The median age at first birth for these cohorts is age 27.5 and therefore more than two years higher than for the younger cohorts.

For females, the first birth pattern is not as homogenous as for the older male cohorts. It might be best described as: Postponement, acceleration and postponement. The cohorts 1948-1964 had their first birth relatively late. The median age at first birth for these cohorts was age 24. The cohorts 1965-1974 were slightly younger at first birth. The cohorts born 1980 or later have their children at later ages again.

2 It should be noted that the EES is not designed for stand-alone analysis of fertility patterns. For this purpose the data should be merged with the Russian Generations and Gender Study. This section is proving fertility estimates for demonstrating purposes only. 
Figure 2a: Kaplan-Meier-survival curves to first child, males

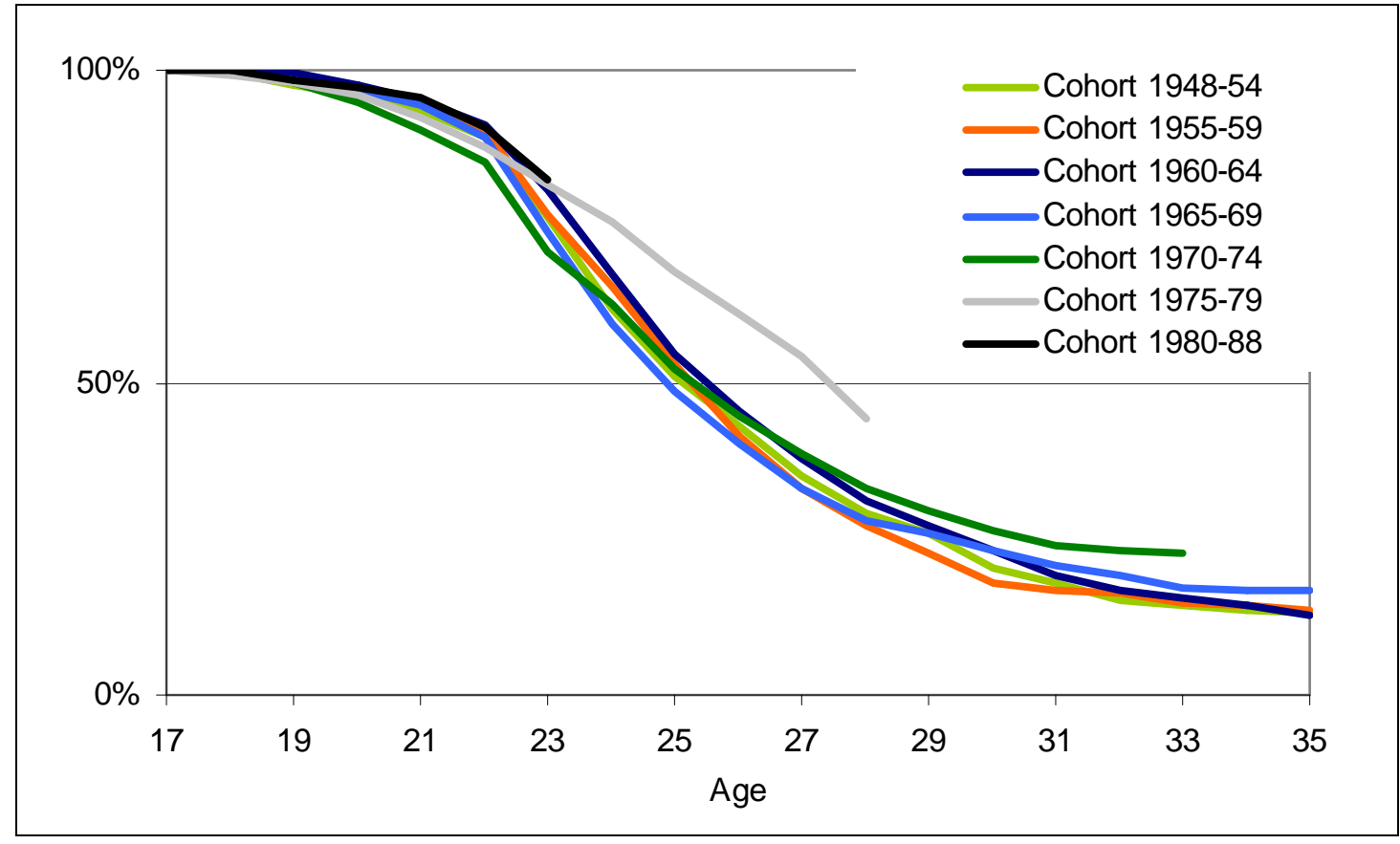

Figure 2b: Kaplan-Meier-survival curves to first child, females

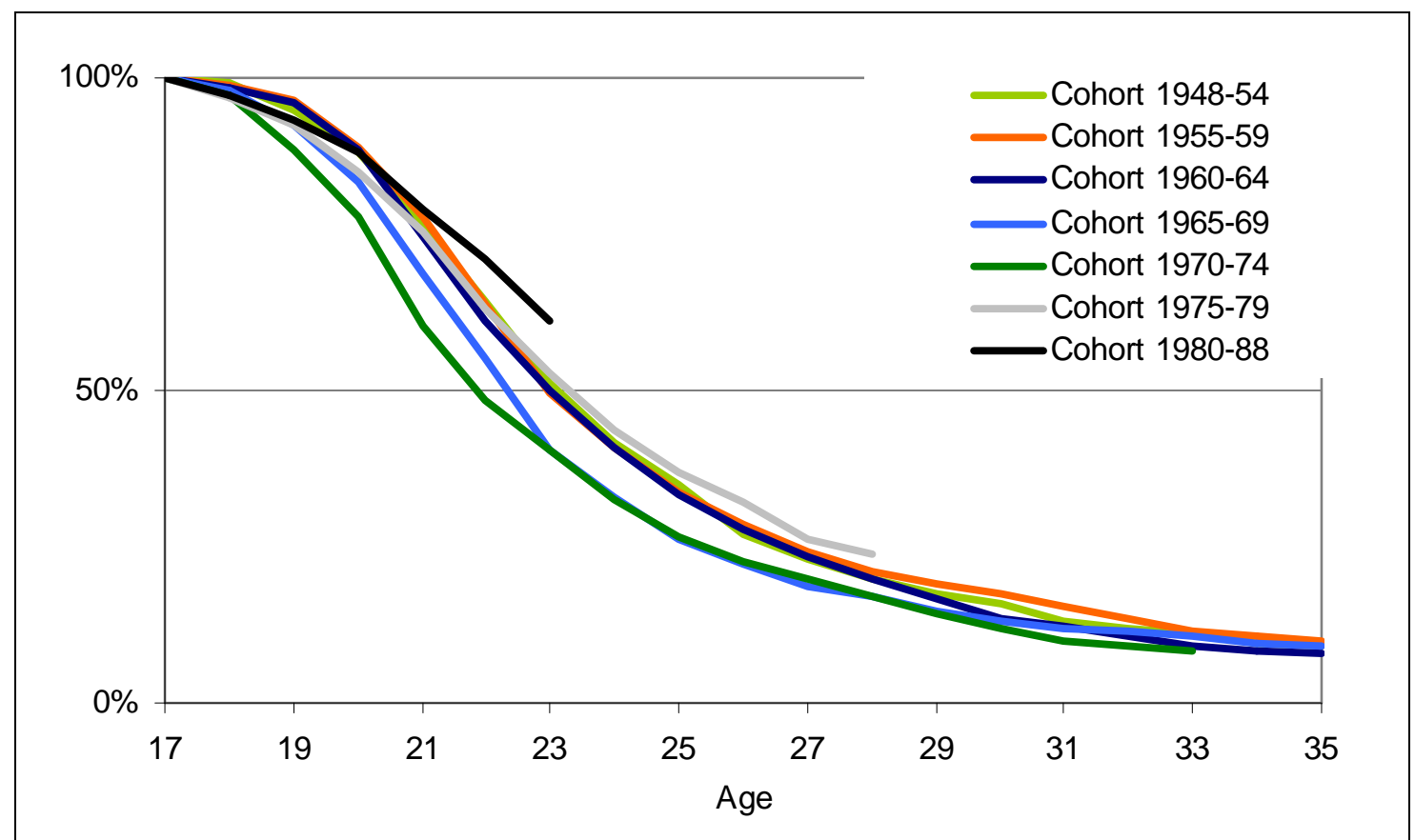




\subsection{Results from event history model}

In this section, we estimate a first birth model. For this analysis, we have backdated the date of childbirth by nine months. By this procedure, we make sure that we measure the employment status before pregnancy. This is particularly of importance for females since they often reduce their labour market participation after pregnancy and childbirth. However, we are unable to take into account that women reduce their labour market activities in anticipation of a pregnancy. Because of backdating the date of childbirth by nine months, we are unable to consider births that have happened until September of the year the respondent turned age 17. We furthermore censored the cases at age 45. This leaves a sample of 5,003 births.

Table 18 displays the results from a piecewise constant model. The only control variables in the model are age (process time), cohort and activity status. The age profile is bell-shaped. For females, the highest intensity of childbirth is at ages 2024, for males at ages 25-29. The results of the cohort variable support the previous analysis with the Kaplan-Meier survival curves. The activity status shows the expected pattern. To be in education cuts first birth risks roughly in half (compared to being employed). Unemployment and other types of activities reduce transition rates significantly for the male population. For females, unemployment has a positive but insignificant impact on first birth risks. Other activities significantly accelerate childbearing for females. 
Table 18: Transition to first birth, relative risks, piecewise constant model

\begin{tabular}{|l|c|c|}
\hline & Males & Females \\
\hline Age & & \\
Age 17-19 & $0.21^{* * *}$ & $0.88^{* * *}$ \\
Age 20-24 & 1.01 & $1.55^{* * *}$ \\
Age 25-29 & 1 & 1 \\
Age 30-34 & $0.43^{* * *}$ & $0.64^{* * *}$ \\
Age 35-39 & $0.25^{* * *}$ & $0.28^{* * *}$ \\
Age 40-45 & $0.10^{* * *}$ & $0.07^{* * *}$ \\
& & \\
Activity status & & \\
In Education & $0.32^{* * *}$ & $0.41^{* * *}$ \\
Employment & 1 & 1 \\
Unemployment & $0.54^{* * *}$ & 1.23 \\
Other activity & $0.27^{* * *}$ & $1.43^{* * *}$ \\
Missing & $0.62^{* * *}$ & $0.66 * * *$ \\
Cohort & & \\
1948-1954 & 1 & $1.25^{* * *}$ \\
1955-1959 & $0.99^{* * *}$ & 0.92 \\
1960-1964 & 0.94 & $0.77^{* * *}$ \\
1965-1969 & 0.96 & 1.03 \\
1970-1974 & $0.95^{* * *}$ & $1.16^{* *}$ \\
1975-1979 & & \\
1980-1988 & & \\
\hline
\end{tabular}

Notes: $* * *: \mathrm{p} \leq 0.01 * *: 0.01 \leq \mathrm{p} \leq 0.05 *$ : $0.05 \leq \mathrm{p} \leq 0.10$.

\subsection{Sensitivity analysis}

In a final step, we investigated how stable the results are with respect to imputed cases. For this reason, we estimated three different kinds of models. The first model only includes age, cohort and activity status (as the model in section 3.3). The second model controls also for whether dates have been imputed or the career includes odd cases. In the third model, we omitted all odd cases or cases with imputed dates. We only conducted this sensitivity investigation for male respondents. The results are displayed in Table 19. The Table shows that the imputation of dates and/or the omission of "odd” cases from the analysis have no major impact on the results. 
Table 19: Transition to first birth, relative risks, piecewise constant model, sensitivity analysis, males

\begin{tabular}{|c|c|c|c|}
\hline & $\begin{array}{c}\text { Model 1: Model including age, } \\
\text { activity status and cohort }\end{array}$ & $\begin{array}{l}\text { Model 2: Controlled for } \\
\text { odd and omitted cases }\end{array}$ & $\begin{array}{l}\text { Model 3: Odd and imputed } \\
\text { cases omitted }\end{array}$ \\
\hline \multicolumn{4}{|l|}{ Age } \\
\hline Age 17-19 & $0.21 * * *$ & $0.21 * * *$ & $0.21 * * *$ \\
\hline Age 20-24 & 1.01 & 1.00 & 0.98 \\
\hline Age 25-29 & 1 & 1 & 1 \\
\hline Age 30-34 & $0.43 * * *$ & $0.43 * * *$ & $0.42 * * *$ \\
\hline Age 35-39 & $0.25 * * *$ & $0.25 * * *$ & $0.23 * * *$ \\
\hline Age 40-45 & $0.10 * * *$ & $0.11 * * *$ & $0.08 * * *$ \\
\hline \multicolumn{4}{|l|}{ Activity status } \\
\hline In Education & $0.32 * * *$ & $0.31 * * *$ & $0.31^{* * *}$ \\
\hline Employment & 1 & 1 & 1 \\
\hline Unemployment & $0.54 * * *$ & $0.54 * * *$ & $0.52 * * *$ \\
\hline Other activity & $0.27 * * *$ & $0.28 * * *$ & $0.29 * * *$ \\
\hline Missing & $0.62 * * *$ & $0.63 * * *$ & $0.62 * * *$ \\
\hline \multicolumn{4}{|l|}{ Cohort } \\
\hline 1948-1954 & 1 & 1 & 1 \\
\hline $1955-1959$ & 0.94 & 0.94 & 0.87 \\
\hline $1960-1964$ & 0.96 & 0.96 & 0.92 \\
\hline 1965-1969 & 0.97 & 0.96 & 0.89 \\
\hline $1970-1974$ & $0.85 * *$ & $0.84 *$ & $0.79 * *$ \\
\hline $1975-1979$ & $0.61 * * *$ & $0.62 * * *$ & $0.60 * * *$ \\
\hline $1980-1988$ & $0.59 * * *$ & $0.59 * * *$ & $0.55 * * *$ \\
\hline \multicolumn{4}{|l|}{ Dates imputed } \\
\hline Education & & 0.00 & \\
\hline Job date & & 1.03 & \\
\hline Other activity & & 0.00 & \\
\hline \multicolumn{4}{|l|}{ Odd cases } \\
\hline Education & & 0.54 & \\
\hline Job date & & 1.10 & \\
\hline Other activity & & 0.89 & \\
\hline
\end{tabular}

Notes: ***: $\mathrm{p} \leq 0.01 * *: 0.01 \leq \mathrm{p} \leq 0.05 *: 0.05 \leq \mathrm{p} \leq 0.10$. 


\section{Concluding Remarks}

This paper documented how the Russian Education and Employment Survey (EES) had been cleaned so that it can be used for event history modelling. Our overall assessment is that the data is of fairly good quality. There were only few episodes with inaccurate starting and ending dates. We noticed only very few "odd" cases. The exclusion of these cases in our first birth analysis did not change the results much. Nevertheless, there are also some pitfalls of this data. A particular drawback is that we are often not able to distinguish non-response from "does not apply”. This particularly pertains to the fertility career, where it was impossible to distinguish childless respondents from those who failed to report their fertility career. Such drawback in the fertility career can be ironed out by combining the data with the Gender and Generation Survey (GGS). For the employment and educational career, it is not possible to double-check with the GGS data in the same manner.

\section{Acknowledgements}

The authors would like to thank Sunnee Billingsley and Rainer Walke for valuable comments on code and paper. We thank Alina Pelikh for the recoding of the regional information.

\section{References}

Independent Institute for Social Policy (2005): Education and Employment Survey on Russia - Technical Report, Moscow 2005.

Walke, Rainer/ Kreyenfeld, Michaela (2006): Spelljoin. A Stata-.ado file to join two spell data sets. Max Planck Institut für demografische Forschung Rostock.

Walke, Rainer/ Kreyenfeld, Michaela (2006): Spellsort. A Stata-.ado file to join two spell data sets. Max Planck Institut für demografische Forschung Rostock. 


\subsection{Variable overview}

$\begin{array}{ll}\text { Bid } & \text { Respondent's id } \\ \text { SPELL } & \text { Number of episode } \\ \text { BEGIN } & \text { Start of episode, since January of year respondent turned 17 } \\ \text { END } & \text { End of episode, since January of year respondent turned } 17 \\ \text { Sex } & \text { Sex of respondent } \\ \text { bh4y } & \text { Year of birth of respondent }\end{array}$

EDU EDU: Episode from educational career

co10 EDU: Education interrupted?

$\mathbf{0 1 1}$ EDU: Type of education

$\mathbf{0 1 2}$ EDU: Diploma received?

$\mathbf{0 1 3}$ EDU: Full, part-time study?

o9ck EDU: Main activity? at end

o9cs EDU: Main activity? at start

JOB JOB: Episode from main employment career

$\mathbf{z 1 5}$ JOB: Occupation

$\mathbf{z 1 6}$ JOB: Type of employee

z17 JOB: Ownership

$\mathbf{z 1 8}$ JOB: Industry

$\mathbf{z 1 9}$ JOB: Position, at end

z19s JOB: Position, at start

z20 JOB: Working hours/week, at end

z20s JOB: Working hours/week, at start

z21 JOB: Working schedule/week, at end

z21s JOB: Working schedule/week, at start

JOB2 JOB2: Episode from $2^{\text {nd }}$ job career

d23 2nd JOB: Occupation

d24 2nd JOB: Type of employee

d25 2nd JOB: Ownership

d26 2nd JOB: Industry

d27 2nd JOB: Position, at end

d27s 2nd JOB: Position, at start

d28 2nd JOB: Working hours/week, at end

d28s 2nd JOB: Working hours/week, at start

d29 2nd JOB: Working schedule/week, at end

d29s 2nd JOB: Working schedule/week, at start

OTHER OTHER: Episode from other activity career

r31cs OTHER: Main activity at start

r31ck OTHER: Main activity at end

r32s_c OTHER: Type of leave

ob_code OTHER: Type of non-employment

UNEMP UNEMP: Unemployment benefits received

UNEMP_r31cs UNEMP: Unemployment benefits received, main activity

UNEMP_r31s_c UNEMP: Occupation type, (unemployed) 
MIG

m5

m6

m7

m8

m5new

PARITY

IMP_EDU

IMP_JOB

IMP_OTH

IMP_SEC

IMP_UNE

IMP_RES

IMP_FER

ODD_EDU

ODD_JOB

ODD_OTH

ODD_SEC

ODD_MIG
MIG: Episodes from residential career

MIG: Region code

MIG: Type of settlement

MIG: Distance

MIG: Reason

MIG: Region code (cleaned)

Number of births

Dates educational career imputed

Dates main employment career imputed

Dates other activity career imputed

Dates second job career imputed

Dates unemployment career imputed

Dates residential career imputed

Dates fertility career imputed

Odd educational career

Odd main employment career

Odd other activity career

Odd second job career

Odd residential career 